\title{
Selection of Materials for Green Construction: A Review
}

\author{
Geeta Mehta ${ }^{1}$ Amit Mehta ${ }^{2}$ Bidhan Sharma ${ }^{3}$ \\ ${ }^{1}$ Assistant Professor, Department of Civil Engineering, Lovely Professional University, Phagwara India \\ ${ }^{2}$ Professor, Department of Civil Engineering, Chandigarh University, India \\ ${ }^{3}$ Student M.Tech Structural Engineering, Lovely Professional University, Phagwara India
}

\begin{abstract}
Go Green has become a global slogan today. We desperately need to save the environment which is the resource of life on earth. Unfortunately the development in technology is clubbed with the diminishing of the resources or polluting the environment. The various factories and industries, automobiles, mining processes are causing damage to our environment. It has been a big challenge for technologists, engineers and scientists to save environment and natural resources without compromising with the quality of performance, development rate and comfort level of society. We have come a long way in developing the materials and techniques which may help to save environment and control depleting resources for future generation. Green buildings is a concept on the same theory. In the effective view green construction includes, increasing energy efficiency of a building usinggreen natural or renewable resources instead of non-renewable resources. In this paper we are presenting the factors to be considered to decide the selection of materials for green construction.
\end{abstract}

Keywords: Energy efficient, green construction, improved air quality, material efficiency, renewable resources.

\section{Introduction}

Building and construction activities worldwide consume 3 billion tons of raw materials each year and represent 40 percent of total global use [1]. It isbroadly estimated that buildings worldwide consume about 40 per cent of the planet's materials resources and 30 per cent of its energy and generates between 10 and 40 per cent of the solid waste streams in most countries [2]. Using green building materials and products promotes conservation of dwindling non-renewable resources. In addition,integrating green building materials into construction projects can help reduce the environmental impacts associated with the extraction, transportation, processing, fabrication, installation, reuse, recycling, and disposal of construction industry source materials.The manufacture of many of the materials used in buildings require the consumption of large amounts of energy derived from the fossil fuels and the displacement of mega-tons of earth during the course of mining. The energy input in GJ/ton for aluminum is 190, plastics 80-100, steeland other metals 30-50, glass 20 and cement/concreteproducts 1.3-5 [3]. But for every ton of cement produced about 2 tons of raw materials must be mined; nearly one ton of $\mathrm{CO}_{2}$ and up to $6 \mathrm{~kg}$ of $\mathrm{NO}_{2}$ gasses are produced [4]. Building, therefore, contributes significantly to global ecological degradation and greenhouse gas emissions.If we want to sustain our urban future there is no option but to build in ways that not only reduce environmental damage but which improve the health of ecosystems and protect natural resources.

The wise choice in this respect is to adopt the "green building" practice. It is a process to create buildings and infrastructure that minimize the useof resources, reduce harmful effects on the ecology and create healthier environments forpeople. Greenbuildings are expected to exhibit a high level of environmental, economicand engineering performance that includes [5]:

- Energy efficiency and conservation

- Improved indoor air quality

- Resource and material efficiency

- Reduced maintenance/replacement costs over the life of the building

- Occupant's health and productivity

- Proximity to public transport system

- Improved environmental quality covering air, water, land and ecosystems

\section{Principles Of Material Selection}

Research:This step involves gathering all technical information to be evaluated,including manufacturers' information such as Material Safety Data Sheets (MSDS), Indoor Air Quality (IAQ), test data, product warranties, source material characteristics, recycled content data, environmental statements, and durability information. In addition, this step may involve researching other environmental issues, building codes, government regulations, building industry articles, model green building product specifications, and other sources of product data [6]. Research helps identify the full range of the project's building material options. 
Evaluate:This step involves confirmation of the technical information, as well as filling in information gaps.Evaluation and assessment is relatively simple when comparing similar types of building materials using the environmental criteria. However, the evaluation process is more complex when comparing different products with the same function. Then it may become necessary to process both descriptive and quantitative forms of data.

Selection: This step often involves the use of an evaluation matrix for scoring the project-specific environmental criteria. The total score of each product evaluation will indicate the product with the highest environmental attributes. Individual criteria included in the rating system can be weighted to accommodate project-specific goals and objectives. Materials with the best score are used for the purpose they serve.

\section{Materials}

The term "materials" refers to all the physical substances that are assembled to create the interior and exterior of a building. Today most buildings are constructed from a multitude of materials, each with very specific functional demands and complex assembly requirements. For instance, an exterior wall assembly contains materials that keep the rain and wind out, thermally insulate the inhabitants from exterior temperatures, structurally support the building and the associated enclosure system, and provide desired interior and exterior finishes. In addition, windows, doors, vents, and other apertures connect to the interior and exterior of the building. The material selection process for a building design and construction is a complex issue.

\section{Desired Properties For Green Material}

There are different criteria that are applied to choosematerials that can be used in green buildings. They include:

i. $\quad$ Materials made of recycled and salvaged agro-industrial wastes

ii. Materials that reduce the quantity used without sacrificing the durability

iii. Materials that are bio gradable

iv. Materials with low emission of volatile organic chemicals (VOC)

v. Materials that avoid toxic emissions or does not add to the ozone depletion

vi. Natural or minimally processed products

vii. Alternatives to natural wood but not made of PVC

viii. Products that reduce or minimize pesticide treatments and reduce pollution

ix. Materials that save energy and water

x. Products that reduce environmental impacts during construction, demolition, renovation or retrofitting.

\section{Factors To Be Considered Before Selecting Material}

i. Natural, plentiful or renewable - Are the products made from material that is rapidly renewable such as cork or bamboo? Wood products are also a renewable resource. Many engineered wood products are made from fast growing trees such as aspen and require less wood to make them than conventional lumber.

ii. Recycled content - Using material with recycled content not only reduces strain on our landfills, but reduces the need for raw material. Paper, cardboard, plastic, steel and aluminum are a few of the most commonly recycled materials. Recycled paper is used in cellulose insulation and paper countertops. Plastic is used in carpet. Metals that are recycled can be made into their original form.

iii. Reusability and recyclability - Many products, such as metals, can be recycled after their useable life. Others can be salvaged and reused somewhere else.

iv. Durability - Choose products that will stand the test of time and require little maintenance. This will save time, money and energy on repairs at a later date.

v. Embodied Energy - This is the energy used to produce, transport and install a product or material in the place where it will be used. Choose local products when possible and products that do not require a large amount of energy to produce.

vi. Air Quality - Products like carpet, cabinetry, plywood and paint can contain petroleum products or formaldehyde and off gas VOCs (Volatile Organic Compounds). There are now many products available that give off little or no VOCs. These products will give you a healthier home to live in. When you are not able to find suitable products, ventilate the new or remodeled space prior to moving into it. Open windows and doors when possible to remove the VOCs from the home.

vii. Waste Reduction - Choose material that does not create a lot of waste and can be used efficiently.

From the above discussed criteria or factors that are to be considered while selecting the materials to be used in green construction can be organized around the following aspects that represent areas of improvement to which the building material/product can contribute to [7]:

- Resource Efficiency. 
- Energy Efficiency.

- Water Conservation.

- Indoor Air Quality and

- Affordability

Resource Efficiency can be accomplished by utilizing materials that meet one or more of the following criteria:

i. Recycled Content: Products with identifiable recycled content, including postindustrial content with a preference for postconsumer content.

ii. Natural, plentiful or renewable: Materials harvested from sustainably managed sources, preferably having a certification (e.g., certified wood), by an independent third party.

iii. Resource efficient: manufacturing process: Products manufactured with resource-efficient processes, that aim at reducing energy consumption, minimizing waste (recycled, recyclable and or source reduced product packaging), and reducing greenhouse gas emissions.

iv. Locally available: Building materials, components, and systems found locally or regionally, saving energy and resources in transportation to the project site.

v. Salvaged, refurbished, or remanufactured: Materials and products that were not disposed of but renovated repaired, restored, or generally products whose appearance, performance, quality, functionality, or value was improved.

vi. Reusable or recyclable: Selected materials that can be easily dismantled and reused or recycled at the end of their use life.

vii. Recycled or recyclable product packaging: Products enclosed in recycled content or recyclable packaging.

viii. Durable: Materials that are longer lasting or are comparable to conventional products with long life expectancies.

Energy Efficiency can be maximized by utilizing materials, components and systems that help reduce energy consumption in buildings and facilities.

Water Conservation can be obtained by utilizing products, materials and systems that help reduce water consumption in buildings and landscaped areas, and increase water recycling and reuse.

Indoor Air Quality can be enhanced by utilizing materials that meet one or more of the following criteria:

i. Low or non-toxic: Materials that emit few or no carcinogens, reproductive toxicants, or irritants as demonstrated by the manufacturer through appropriate testing.

ii. Minimal chemical emissions: Products that have minimal emissions of Volatile Organic Compounds (VOCs). Products that also maximize resource and energy efficiency while reducing chemical emissions.

iii. Low-VOC assembly: Materials installed with minimal VOC-producing compounds, or no-VOC mechanical attachment methods and minimal hazards.

iv. Moisture resistant: Products and systems that resist moisture or inhibit the growth of biological contaminants in buildings.

v. Healthy environment maintained: Materials, components, and systems that require only simple, non toxic, or low VOC methods of cleaning.

Affordability can be considered when building product life-cycle costs are lower or comparable to those of "conventional" products, or are within a project-defined percentage of the overall budget.

\section{Life Cycle Assessment}

While there are many different approaches to the detailed evaluation of construction materials, in environmental performance terms there is little disagreement as to aspects of performance which should be definitely considered. Comprehensive assessments of materials performance must be in the context of complete life cycle (Life Cycle Assessment, LCA).An LCA considers the following aspects:

\footnotetext{
i. Extraction, processing and transportation of raw materials.

ii. Production, transport anddistributionofresultingproducts.

iii. Use, re-use and maintenance.

iv. Recycling and final disposal.
}

The European division of the Society for Environmental Toxicology and Chemistry (SETAC)describes the purpose of LCA as a process designed to [11]:

i. Evaluate the environmental burdens associated with a product, process or activity identifying and quantifying use of energy, materials and waste discharged into the environment.

ii. Determine the impact of these resources and waste and their environmental discharges. 
iii. Evaluate and put into practice, opportunities for improvement.

\section{Conclusions}

It can be concluded that there are various materials which can be adopted for green construction, but we need to select the material which may fulfill maximum if not all the factors discussed above. The materials chosen must increase energy efficiency of the structure. A code for the selection criteria for the green material if being developed will help in making the complex issue easy for the common people. This way we can save the environment as well as make the efficient use of economy as well as resource.

\section{References:}

[1]. Burton Hamner (2007). "Effects of Green Purchasing Strategies on SupplierBehaviour", Greening the Supply Chain, 2, 25-37, 2007.

[2]. C.R. Carter. "Inter-organizational atecedentsand determinants of environmental purchasing: Initial Evidence from the Consumer Products Industry", Decision Sciences, 29(3), 659-684, 1996.

[3]. IbuchimOgunkah and Junli Yang, "Investigating Factors Affecting Material Selection: The Impacts on Green Vernacular Building Materials in the Design-Decision Making Process", MDPI Journals on buildings, 2, 1-32, 2012.

[4]. Bidhan Sharma andGeeta Mehta, "An Experimental Study on Compressive Strength of Concrete with Natural Pozzolana (Clay)", International Journal of Engineering Research \& Technology (IJERT),3(5), 2014.

[5]. H. Klee, The cement sustainability initiative, In: 3rd Internationalsymposiumsustainability in cement concrete, Istanbul, Turkey, 21-23 May (2007).

[6]. Junli Yang andIbuchim Cyril B. Ogunkah, "A Multi-Criteria Decision Support System for the Selectionof Low-Cost Green Building Materials and Components", Journal of Building Construction and Planning Research, 1, 89-130, 2013.

[7]. Bahia Rabehi, KhaledBoumchedda and YoucefGhernouti, "Study of calcinedalloysite clay as pozzolanic material and its potential use in mortars", International Journal of the Physical Sciences,7(31),5179-5192, 2011.

[8]. Annika varnäs, BeritBalfors and Charlotta faith, "Environmental consideration in procurement of construction contracts: current practice, problems and opportunities ingreen procurement intheSwedishconstructionindustry", Journal of Cleaner Production, 17(13), 124-122, 2007

[9]. Rances Castillo Lara, Mathieu Antoni, Adrian Alujas Diaz, "Study of the additionofcalcinedclays in the durability of concrete." RevistaIngeniería de Construction, 2011.

[10]. RetnoRahardjati, Dr. Mohd. FarisKhamidi, "Green Building Rating System: The need of Material Resources Criteria in Green Building Assessment", 2nd International Conference on Environmental Science and Technology, 6, 148-151.

[11]. Anjan K. Chatterjee, "Sustainable construction and green buildings on the foundation of building ecology", The Indian Concrete Journal, 1, 27-30, 2009. 